\title{
Doppler Winds Lidar Technology Development and Demonstration
}

\author{
Jinxue Wang \\ Raytheon Santa Barbara Remote Sensing, Goleta, CA 93117 \\ Michael T. Dehring ${ }^{\dagger}$ \\ Michigan Aerospace Corporation, Ann Arbor, MI 48108 \\ Floyd E. Hovis \\ Fibertek, Inc., Herdon, VA 20170 \\ and \\ Berrien Moore III $^{\S}$ \\ University of New Hampshire, Durham, NH 03824
}

\begin{abstract}
High resolution (both spatial and temporal) and accurate tropospheric wind profiling from spaceborne platforms has been one of the most wanted capability by both DOD and civilian user communities to support weather forecasting, national defense and homeland security applications. This capability is still only a dream after decades of research and development due to a variety of reasons. With the recent rapid advancement of diode-pumped solid-state lasers and advanced detectors, space-based Doppler winds lidar missions are much more feasible and promising than ever before. In this paper, we will first discuss the strong needs for spacebased Doppler winds lidar. We will then present a brief overview of the GroundWinds and BalloonWinds projects in Section II and III, which are intended as direct detection Doppler wind lidar (D3WL) technology development and demonstration test-bed sponsored by the National Oceanic and Atmospheric Administration (NOAA). In Section IV, we will discuss the design and fabrication of a high energy laser transmitter prototype for space-based Doppler winds lidar supported by Raytheon's internal research and development (IRAD) program. This laser transmitter prototype is intended to enhance the technology readiness level (TRL) and reduce the risk of future space-based Doppler winds lidar development.
\end{abstract}

\section{Acronyms}

$\begin{array}{ll}\text { Lidar } & =\text { Light Detection and Ranging } \\ D W L & =\text { Doppler Winds Lidar } \\ D 3 W L & =\text { Direct Detection Doppler Winds Lidar } \\ S H G & =\text { Second Harmonic Generation } \\ T H G & =\text { Third Harmonic Generation } \\ K T P & =\text { Potassium titanyl phosphate } \\ L B O & =\text { Lithium triborate } \\ R T P & =\text { Rubidium titanyl phosphate } \\ I R A D & =\text { Internal Research and Development } \\ T R L & =\text { Technology Readiness Level } \\ \text { LRRP } & =\text { Laser Risk Reduction Program } \\ \text { NPOESS } & \text { National Polar Orbiting Environmental Satellite } \\ I P O & =\text { Integrated Program Office } \\ \text { NASA } & =\text { National Aeronautics and Space Administration } \\ \text { NOAA } & =\text { National Oceanic and Atmosphere Administration }\end{array}$

\footnotetext{
* Technical Director \& Manager, Active Sensors, Raytheon SBRS, 75 Coromar Drive, B32/15, Goleta, CA 93117

${ }^{\dagger}$ Manager-Lidar Systems, Michigan Aerospace Corp., Ann Arbor, MI 48104

* Assistant Vice President, Fibertek, Inc., Herdon, VA 20170

${ }^{\S}$ Professor and EOS Director, University of New Hampshire, 39 College Road, Durham, NH 03824
} 


\section{Introduction}

Winds speed and direction have always been important to the daily lives of human beings. Wind was probably one of the first atmospheric variables measured. Wind vanes were used by the ancient Egyptians and Chinese to measure the direction of air flow. The Greeks measured winds by observing the directions and the degree of deformation of trees and waves in grass fields. Aristotle wrote about relationships between cloud formation and winds. Human beings have always had a strong need and desire to know and measure winds because of the realization of how this atmospheric phenomenon affects people's daily lives. Throughout human history, various winds measurement techniques and devices ranging from relatively simple strain-gauge wind sensors to sophisticated winds radars and lidars have been developed.

Despite the long history of human's fascination with winds and development of various types of wind sensors, there is still no direct observation of global wind profiles throughout the troposphere and lower stratosphere (approximately 0 to $30 \mathrm{~km}$ ) even though these measurements are critical to improved long-range weather forecasting, better hurricane tracking, troposphere-stratosphere exchange studies, global pollution and climate studies, etc. Of the 3 important atmospheric variables, namely temperature, moisture, and wind, both atmospheric temperature field and moisture field have been observed routinely from space since the 1960s. Winds field is the only remaining important variable in the equation of atmospheric motion that has not been observed from space. The World Meteorological Organization (WMO) has consistently ranked direct observation of global tropospheric winds profiles from satellites as one of the most challenging and important observations. ${ }^{1}$

Table 1 lists types of winds data that are currently used in numerical weather forecasting and various transport and climate studies. These data are limited to: 1) surface data from surface stations, ships, buoys, and more recently observations by spaceborne scatterometer over ocean; (2) winds profiles from radiosonde networks at selected sites mostly over land. Coverage is very limited, especially in the southern hemisphere. Instruments and observation qualities are highly variable. All these attributes limit their usefulness; 3) satellite cloud and water vapor motion winds. They tend to be single level at the cloud height. Accurate height assignment has been a problem. Clearly, significant deficiencies exist with current available winds data. Direct measurement of winds speed and directions from space by a Doppler lidar system is generally regarded as the only way to fill the data gaps and meet operational weather forecasting and climate study requirements. Tropospheric winds data is the \#1 unmet Environmental Data Record (EDR) of the US National Polar Orbiting Environmental Satellite Systems (NPOESS). It is becoming increasingly urgent to have the ability to observe global wind fields from satellites.

Table 1. Current wind measurements and their limitations.

\begin{tabular}{|l|l|l|}
\hline Wind Measurement Technique & Comparison to User Requirements & Problems \\
\hline $\begin{array}{l}\text { Rawinsonde } \\
\text { In-situ measurement }\end{array}$ & $\begin{array}{l}\text { Inadequate coverage. Very few } \\
\text { measurements over oceans and large } \\
\text { part of the southern hemisphere }\end{array}$ & $\begin{array}{l}\text { Biased to land and developed } \\
\text { countries. Expensive per } \\
\text { measurement }\end{array}$ \\
\hline $\begin{array}{l}\text { Aircraft Reported Winds } \\
\text { (ACARS). In-situ measurement }\end{array}$ & $\begin{array}{l}\text { Along aircraft flight paths. Inadequate } \\
\text { vertical and horizontal coverage }\end{array}$ & Biased to aircraft routes only \\
\hline $\begin{array}{l}\text { Ground Radar Profilers } \\
\text { Ground-based remote sensing }\end{array}$ & Inadequate horizontal coverage & $\begin{array}{l}\text { Biased to land and developed } \\
\text { countries. Expensive per } \\
\text { measurement }\end{array}$ \\
\hline $\begin{array}{l}\text { Cloud Motion Winds } \\
\text { Space remote sensing }\end{array}$ & $\begin{array}{l}\text { Inadequate vertical and horizontal } \\
\text { coverage }\end{array}$ & $\begin{array}{l}\text { Height assignment errors } \\
\text { Low accuracy }\end{array}$ \\
\hline $\begin{array}{l}\text { Spaceborne Scatterometers } \\
\text { Space remote sensing }\end{array}$ & $\begin{array}{l}\text { Ocean surface winds. Inadequate } \\
\text { horizontal and vertical coverage }\end{array}$ & $\begin{array}{l}\text { Biased to oceans and surface } \\
\text { layer }\end{array}$ \\
\hline $\begin{array}{l}\text { Water Vapor Tracking Winds } \\
\text { Space remote sensing }\end{array}$ & $\begin{array}{l}\text { Inadequate accuracy and vertical } \\
\text { coverage }\end{array}$ & $\begin{array}{l}\text { Height assignment errors } \\
\text { Low accuracy }\end{array}$ \\
\hline
\end{tabular}

Numerous studies over several decades have shown that Doppler wind lidar is the most promising technique to measure 3-D global wind fields with the needed accuracy, vertical resolution, and spatial resolution. With Doppler winds lidars, winds are derived from direct measurements of Doppler shifts of backscattered laser light by molecules and/or atmospheric aerosols. Since the shifts of backscattered light are small, very high spectral resolution and sensitive detection techniques are needed. There are two basic approaches to measure the Doppler shifts. One is direct measurements using high resolution optical devices such as a Fabry-Perot interferometer. The other approach is optical heterodyning, or coherent detection, which determines Doppler shifts by mixing the 
backscattered laser light with laser source from a stable local oscillator. Both techniques have fairly long history of development and applications. Coherent techniques use the same basic principles as Doppler radar, and rely on backscattering from atmospheric aerosols. Coherent detection can provide very accurate winds measurements in atmospheric regions with adequate amount of aerosol such as the boundary layer. This is in contrast to direct detection, which is able to measure winds from molecular backscatter independent of the aerosol field. The ability of D3WL to measure winds in clean air makes it possible for a space-based DWL to cover the whole troposphere and lower stratosphere $(0-20 \mathrm{~km})$, which is required by the data user communities. However, based on preliminary design studies, such a direct detection lidar needs significant amount of power to operate and requires large mass and volume allocations from the satellite platform. Both direct detection and coherent detection have their advantages and disadvantages depending on the types of applications and measurement requirements. They can complement each other in that coherent detection can target the boundary layer (i.e. $0-3 \mathrm{~km}$ ) and direct detection target the middle and upper troposphere (i.e. $3-20 \mathrm{~km}$ ). This hybrid concept has been suggested by Emmitt. ${ }^{2}$ Such a hybrid system promises to exploit the strengths of the coherent and direct detection system to reduce the laser energy, mass and volume requirements of each system. A baseline mission concept for the demonstration of the proposed hybrid winds lidar system on either the NPOESS platform or a free-flyer satellite is currently being formulated.

The focus of this paper is to discuss the technology development and feasibility demonstration of the direct detection component of a hybrid Doppler winds lidar system. In particular, ground-based and high-altitude balloon-based demonstrations will be presented. The design and testing of a risk-reduction space laser transmitter for direct detection Doppler winds lidar will be discussed. Readers interested in learning more about coherent DWL are encouraged to consult several review papers on coherent winds detection by Menzies and Hardesty, ${ }^{3}$ Huffaker and Hardesty, ${ }^{4}$ and Baker et. al. ${ }^{5}$

\section{Demonstration from Ground Looking Up - GroundWinds}

GroundWinds is a direct detection DWL science and technology test-bed sponsored by NOAA. Prof. Berrien Moore III of the University of New Hampshire (UNH) has been leading the program as the principle investigator (PI). Participating organizations include: University of New Hampshire, Michigan Aerospace Corporation (MAC), Mount Washington Observatory, University of Hawaii, etc. Scientists from NOAA, NASA, MIT Lincoln Laboratory, NPOESS IPO, etc. participated in various program reviews as an advisory group. Two D3WL instruments were developed under this program. One is the GroundWinds NH instrument deployed at Bartlett, New Hampshire (NH). GroundWinds NH uses a 532nm Nd:YAG laser. The other instrument is GroundWinds HI deployed at Mauna Loa Observatory. It uses a $355 \mathrm{~nm}$ Nd:YAG laser. GroundWinds HI is intended as an operational instrument with the ability to measure winds routinely over an extended period of time for research and applications. Figure 1 is a schematic diagram of the GroundWinds D3WL. Commercial Nd:YAG lasers are used. Either 532nm or $355 \mathrm{~nm}$ laser outputs from the laser subsystem are expanded by a beam-expander and then directed by high reflectivity (HR) mirrors and telescope to the atmosphere. Backscattered light by aerosols and molecules is collected by the 0.5 meter diameter telescope and is coupled to a filter box and the receiver subsystem by a $300 \mu \mathrm{m}$ optical fiber cable. The receiver subsystem contains the fiber recycler (U.S. patent \#6,163,380), a molecular Fabry-Perot etalon, an aerosol Fabry-Perot etalon, and two CCD cameras with special circle-to-line-optic (CLIO) devices (U.S. Patent \#4,893,003) to convert the circular Fabry-Perot fringe patterns to linear fringe patterns. ${ }^{6}$ Key instrument parameters for both instruments are listed in Table 2.

Figure 2 shows scatter plots of standard deviations of molecular winds and aerosol winds from a large number of wind profiles taken at the GroundWinds NH site as reported by Dehring et al.. ${ }^{7}$ A precision of $1 \mathrm{~m} / \mathrm{s}$ or better up to 8 $\mathrm{km}$ was achieved. We want to note here that the total deviations in figure 2 are the summation of winds measurement errors and the natural variability of the atmosphere from one measurement to another. Wind measurement random errors are smaller than the standard deviations because they also contain the changes caused by atmosphere variability. Based on modeling and performance simulations, a precision of $0.6 \mathrm{~m} / \mathrm{s}$ can be achieved with GroundWinds. Figure 3 shows scatter plots of standard deviations of molecular winds and aerosol winds from a large number of wind profiles taken at the GroundWinds HI site. For GroundWinds HI, the atmosphere above Mauna Loa has very low aerosol concentration. As a result, aerosol channel signal is very weak, and does not contribute much to the overall measurements. The molecular channel using Rayleigh scattering from atmospheric molecules is the main contributor. GroundWinds HI demonstrated that this technology can provide accurate wind measurements in a clean oceanic air environment that has no or very low aerosol concentration. For more information on GroundWinds instruments, measurement results, and applications, please see papers by Dehring et al., ${ }^{7}$ Nardell et. $a l,{ }^{8}$ and Businger et. $a l .{ }^{9}$ 
Table 2. GroundWinds NH and GroundWinds HI key instrument parameters.

\begin{tabular}{|l|l|l|}
\hline \multicolumn{1}{|c|}{ Parameter } & GroundWinds HI & GroundWinds NH \\
\hline Operating wavelength & $355 \mathrm{~nm}$ & $532 \mathrm{~nm}$ \\
\hline Operating frequency & $10 \mathrm{~Hz}$ & $10 \mathrm{~Hz}$ \\
\hline Power & $3 \mathrm{Watts}$ & $5 \mathrm{watts}$ \\
\hline Laser pulse length & $8 \mathrm{nsec}$ & $8 \mathrm{nsec}$ \\
\hline Laser divergence & $<0.1 \mathrm{mrad}$ & $<0.1 \mathrm{mrad}$ \\
\hline Telescope diameter & $.5 \mathrm{~m}$ & $.5 \mathrm{~m}$ \\
\hline Telescope field of view & $0.1 \mathrm{mrad}$ & $0.1 \mathrm{mrad}$ \\
\hline Molecular etalon gap & $15 \mathrm{~mm}$ & $15 \mathrm{~mm}$ \\
\hline Aerosol etalon gap & $80 \mathrm{~mm}$ & $164 \mathrm{~mm}$ \\
\hline Vertical sample rate & $40 \mathrm{~m}$ & $40 \mathrm{~m}$ \\
\hline Vertical resolution & $240 \mathrm{~m}$ & $240 \mathrm{~m}$ \\
\hline
\end{tabular}

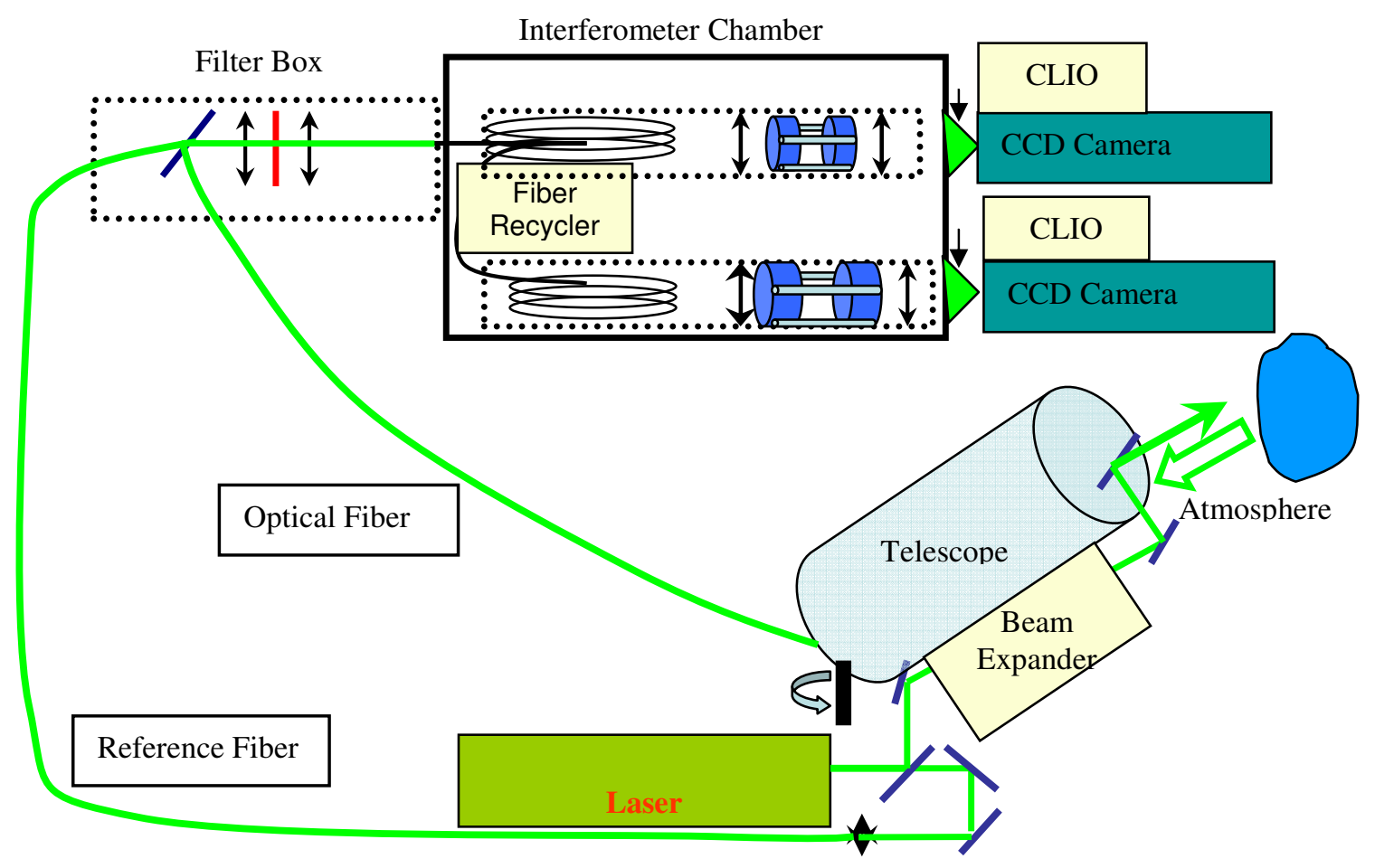

Figure 1. Schematic diagram of GroundWinds NH and GroundWinds HI instruments. 

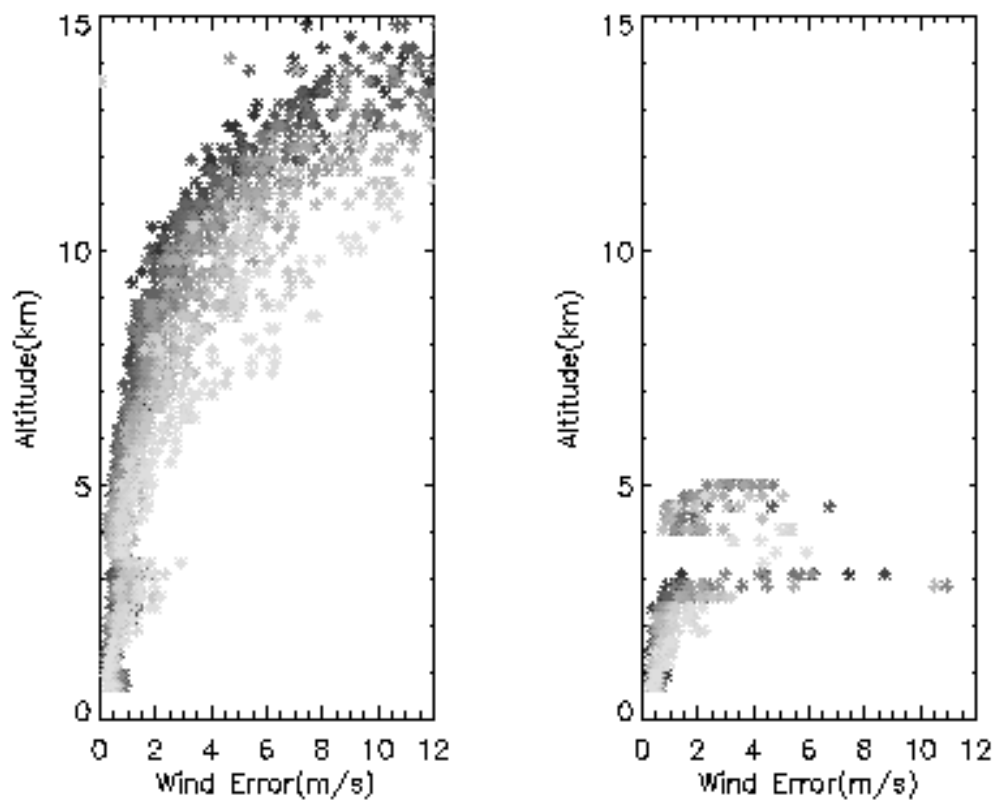

Figure 2. GroundWinds NH horizontal winds standard deviations calculated from molecular channels data (left panel) and aerosol channels data (right panel). The integration time for each wind profile is one minute.
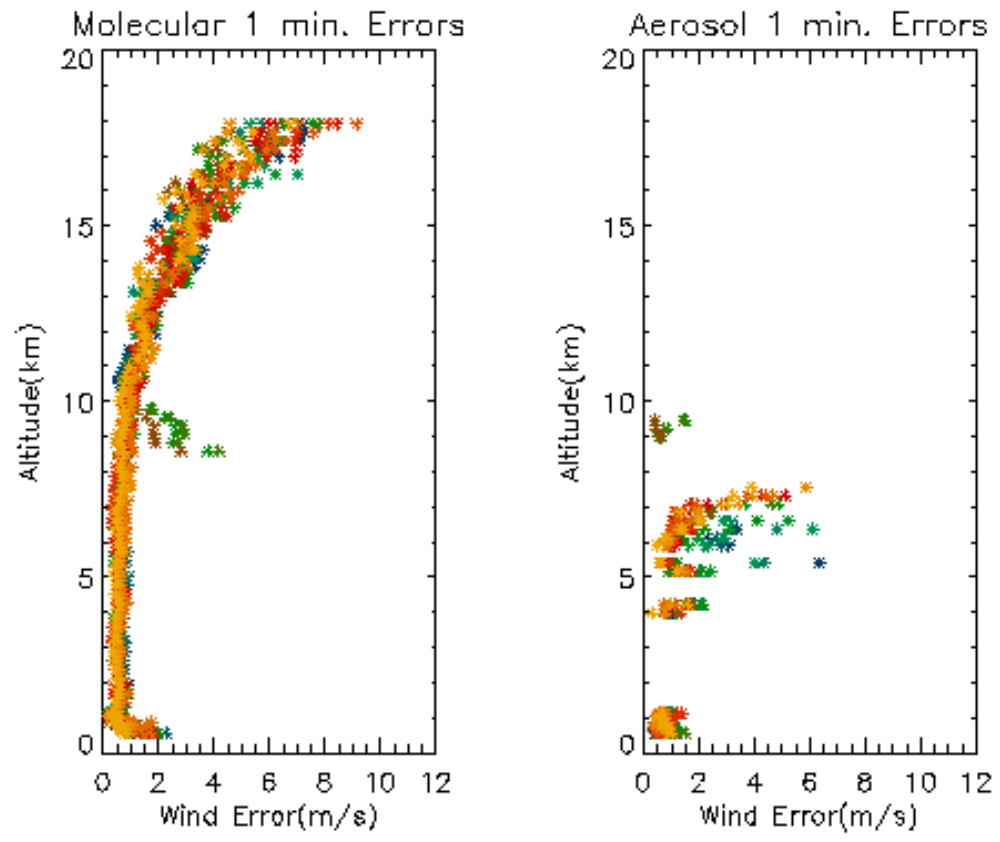

Figure 3. Standard deviations of horizontal winds from molecular channels (left panel) and aerosol channels (right panel) of GroundWinds HI. The integration time for each wind profile is one minute. Due to very low aerosol concentration over the GroundWinds HI site, the only aerosol contributions detected have been from clouds and fog drifting into the line of sight of the instrument. 


\section{Demonstration from High Altitude Balloon Looking Down - BalloonWinds}

With GroundWinds NH in Bartlett, NH and GroundWinds HI in Mauna Loa, HI successfully demonstrating the capability of direct detection DWL to measure atmospheric winds looking up from ground under various aerosol and atmosphere conditions, the next logical step is to validate the operation and models of a direct detection DWL looking down from above the troposphere. The BalloonWinds program, also sponsored by NOAA, was designed to accomplish those objectives. High-altitude balloon at $30 \mathrm{~km}$ altitude provides the needed platform to look though the entire troposphere and demonstrate direct detection DWL wind measurement from surface to $20-30 \mathrm{~km}$ altitude. Professor Berrien Moore III of the University of New Hampshire is the PI of the BalloonWInds project. BalloonWinds participating organizations include: University of New Hampshire, Michigan Aerospace Corporation (MAC), Raytheon Space and Airborne Systems, Air Force Research Laboratory (AFRL), and Fibertek. AFRL provides balloon launch support. Raytheon is responsible for the telescope subsystem, system engineering support, laser transmitter subsystem support, and thermal vacuum testing support. Fibertek is responsible for the diodepumped solid-state laser. The goals of the BalloonWinds mission include: 1) Demonstration of multi-order fringe imaging technique and wind measurement accuracies from a high altitude platform that are commensurate with space-based DWL draft specifications; 2) collecting data under various observing conditions that include high and low clouds, high and low winds, variable boundary layer aerosol conditions, day and nighttime from surface to 28 $\mathrm{km}(2 \mathrm{~km}$ below balloon floating altitude) for model validation and space-based DWL design and simulation. Three launches at the Holloman AFB in New Mexico are planned. The first launch, intended as a test, is scheduled for April 2006. It will be under night and clear sky conditions. The second launch for daytime and partially cloudy conditions will follow soon after in May 2006. The third launch for both day and night and under partially cloudy conditions is scheduled for October 2006. Figure 4 shows the planned time line of the balloon launch. It takes about 2 hours for the balloon to rise slowly through the atmosphere and reach the $30 \mathrm{~km}$ floating altitude. After reaching the floating altitude of about $30 \mathrm{~km}$, a quick system checkout will be conducted to ensure that the laser subsystem can be turned on safely and system alignment is maintained. After the initial checkout, data collection will be initiated. This will last for about 8-10 hours depending on the objectives of each launch. After data collection is completed, descent will be initiated. The payload will be recovered and inspected.

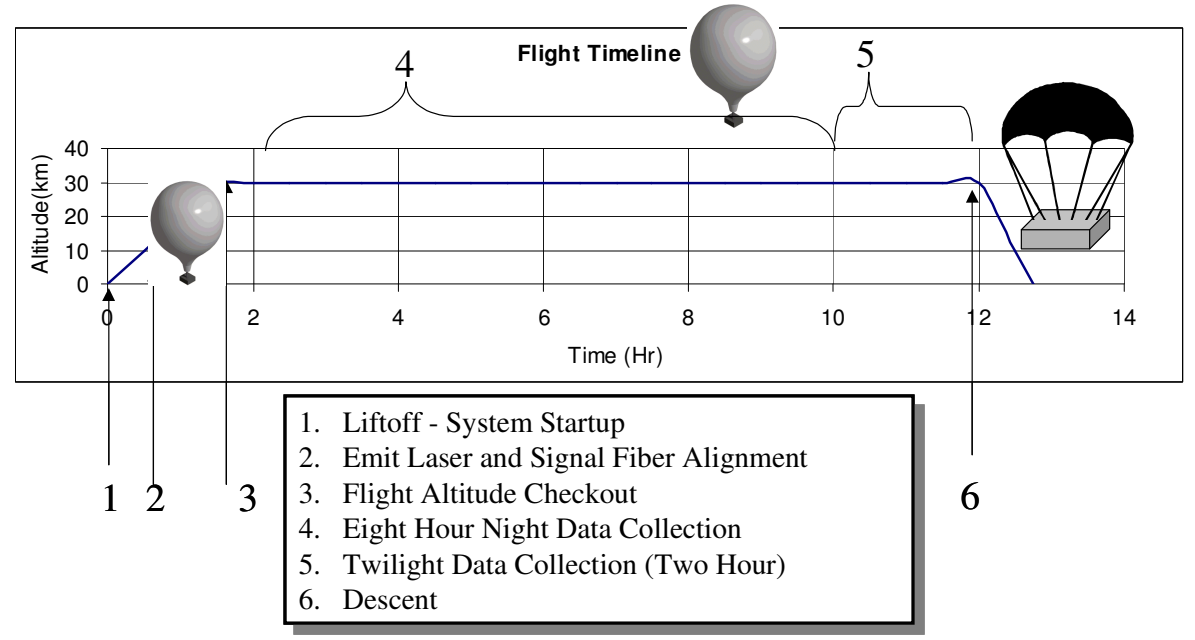

Figure 4. Planned mission timeline of the BalloonWinds launches.

The BalloonWinds instrument is based on the GroundWinds instrument design. However, it has a number of enhancements to meet the requirements of the BalloonWinds mission. The laser subsystem is changed from the commercial flash lamp-pumped solid-state lasers used in GroundWinds systems to a custom-designed diodepumped solid-state Nd:YAG laser, compatible and scalable in energy and power for future space-based DWL missions. ${ }^{10}$ The telescope subsystem is a custom-designed athermal telescope to ensure alignment under significant ambient temperature changes, which the telescope is exposed to. As the balloon rises from ground to floating altitude, ambient temperature can change from the surface temperature of about $35^{\circ} \mathrm{C}$ to $-55^{\circ} \mathrm{C}$ at floating altitude. The interferometer subsystem and chamber were also re-designed to be more compact and rugged. A new electronmultiplying CCD camera from Andor Technology is used in the BalloonWinds receiver subsystem. Figure 5 illustrates the location of various BalloonWinds lidar subsystems on the gondola. Figure 6 is a picture of the BalloonWinds telescope subsystem without the shroud. 


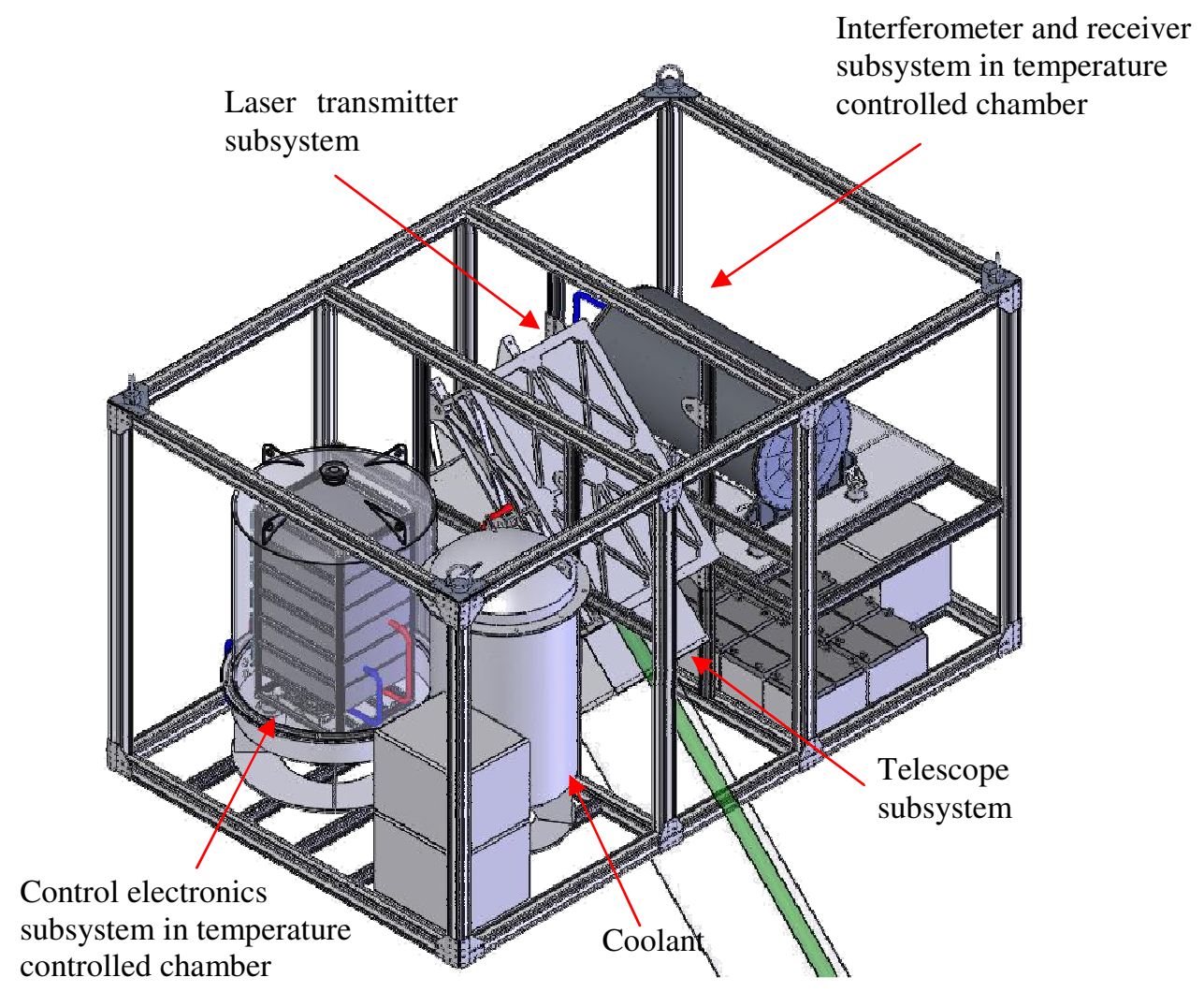

Figure 5. BalloonWinds gondola and major instrument subsystems.

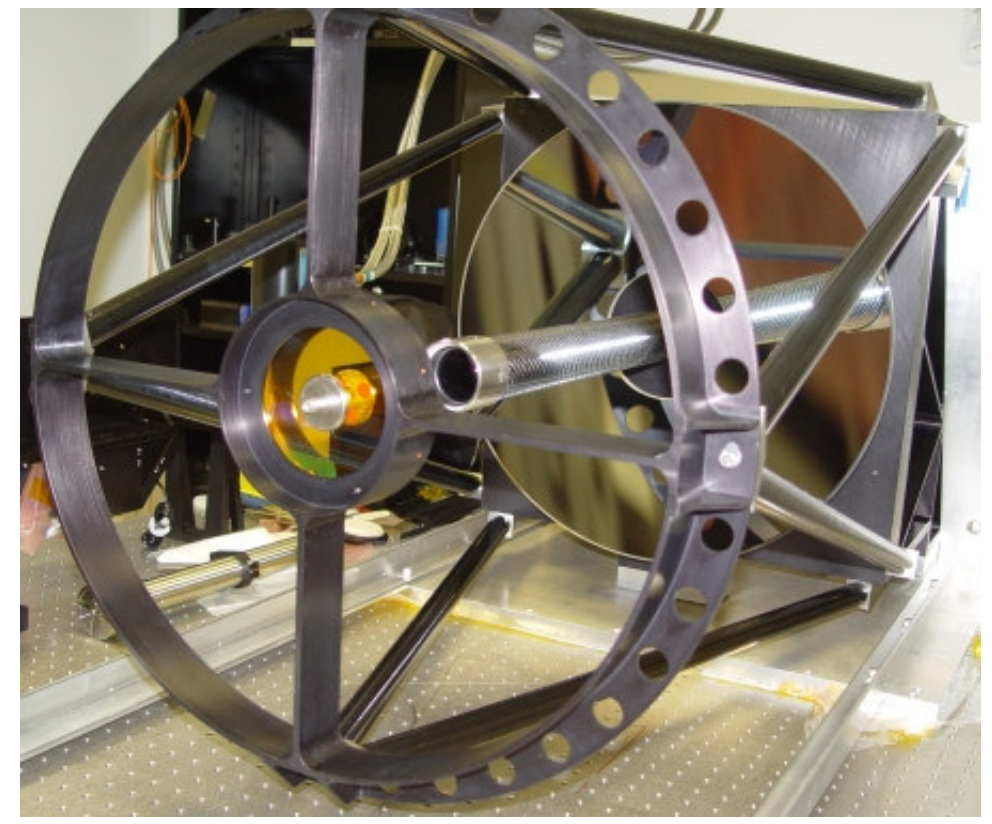

Figure 6. Picture of the BalloonWinds 0.5meter athermal telescope subsystem without the shroud. 
BalloonWinds instrument is currently being integrated at Michigan Aerospace Corp. (MAC). Testing is scheduled to begin in October 2005. Thermal vacuum testing at the Air Force Research Laboratory (AFRL) at Kirkland AFB in Albuquerque is scheduled for February 2006. The first BalloonWinds launch is planned for April 2006. BalloonWinds measurement results and analysis will be reported in future papers.

\section{Space-based DWL Technology Development and Risk Reduction}

As a complementary effort to the BalloonWinds and GroundWinds programs, Raytheon initiated internal research and development (IRAD) projects that are intended to facilitate and enable the transition from GroundWinds and BalloonWinds to a space-based DWL, a very important and challenging next step. Key technology hurdles for space-based DWL include space-qualified laser transmitters and large rotating telescopes. A number of groups have been working on lightweight telescopes and alternative telescope designs such as holographic optical element (HOE) telescope. ${ }^{11,12}$ We decided to focus our IRAD effort on the laser transmitter. Space-qualified laser transmitters remain the tall pole in space-based lidar development. The NASA laser risk reduction program (LRRP) is intended to improve the overall spaceborne laser technology readiness level. ${ }^{13} \mathrm{Dr}$. Upendra Singh from NASA Langley and Dr. William Heap from NASA Goddard Space Flight Center (GSFC) are Co-PI of the program. NASA Langley has been working on 2-um laser development. ${ }^{14,15}$ NASA GSFC focus their efforts on the development of 1-um lasers. However, those efforts are intended to advance the science and basic technologies associated with 1-um and 2-um lasers. Currently, no LRRP funding is available to develop compact and rugged space laser transmitter prototypes for particular missions or programs, which are essential to the development of a space-based DWL. We intend to fill this gap by focusing the Raytheon IRAD effort on the development of a space laser transmitter prototype that will serve as an engineering model and a risk-reduction laser (RRL) for a direct detection Doppler wind lidar (either a stand-alone direct detection DWL or the direct detection part of a hybrid DWL). A compact and rugged engineering risk reduction laser transmitter prototype that has the same basic design is essential to reduce the technical, schedule and cost risk of the flight instrument development. One of the key recommendations from a recent NASA "Space Lasers - Lessons Learned" workshop is "Build and fully test a laser transmitter engineering model". Efforts have been made to leverage previous development and investments by DOD, NASA, and industry. A partnership between Raytheon and Fibertek has been established to develop such a risk reduction laser transmitter prototype by leveraging Fibertek's experiences with a number of recent laser development programs funded by NASA and Raytheon's laser and lidar experiences with DOD programs.

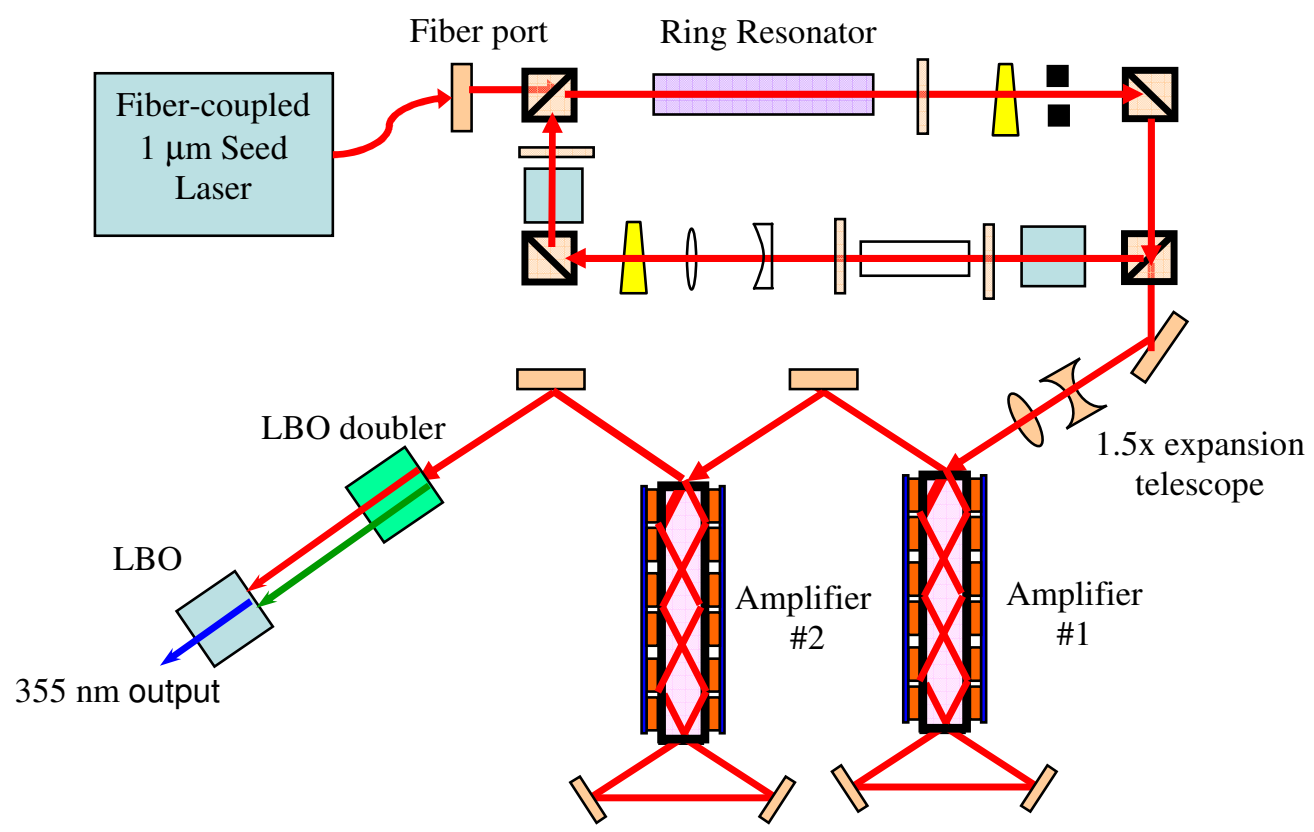

Figure 7. DWL risk reduction laser transmitter prototype optical architecture diagram. 


\section{A. Technical Approaches}

After comprehensive survey of current state-of-the-art solid-state laser technologies and laser transmitter requirements for future space-based lidar missions, we arrived at a set of key requirements for the laser transmitter prototype as shown in Table 3. Figure 7 in the previous page shows the optical architecture of our space laser transmitter prototype. The laser transmitter design incorporates diode-pumped and conductively cooled Nd:YAG slabs as the gain media. The oscillator is a telescopic ring resonator design that can be easily re-configured for a variety of operational scenarios. Since stability over demanding environmental conditions is needed for spaceborne operations, we have developed a design for the ring resonator optical bench that incorporates Zerodur, a low expansion ceramic, as the bench material. In order to achieve the desired single-frequency operation, we have developed a variation of the so-called "ramp and fire" approach ${ }^{16}$ to injection seeding that uses a rubidium titanyl phosphate (RTP) electro-optic modulator to vary the effective cavity length rather than a mirror mounted on a piezoelectric transducer (PZT). The amplifier design for the system is based on the double-sided pumping and cooling approach.

Table 3. 1-micron space laser transmitter risk reduction prototype requirements.

\begin{tabular}{|c|c|c|}
\hline & Threshold Requirements & Goal Requirements \\
\hline Type & $\begin{array}{l}\text { Diode-pumped Nd:YAG, } \\
\text { active Q-switch, seeded }\end{array}$ & $\begin{array}{l}\text { Diode-pumped Nd:YAG, } \\
\text { active Q-switch, seeded }\end{array}$ \\
\hline Wavelength & $1064 \mathrm{~nm}, 355 \mathrm{~nm}, 308-320 \mathrm{~nm}$ & $1064 \mathrm{~nm}, 355 \mathrm{~nm}, 308-320 \mathrm{~nm}$ \\
\hline Pulse Energy & $700 \mathrm{~mJ}$ at $1064 \mathrm{~nm}$ & $1 \mathrm{~J}$ at $1064 \mathrm{~nm}$ \\
\hline THG Efficiency & $45 \%$ & $50-55 \%$ \\
\hline PRF & $50 \mathrm{~Hz}$ & $100 \mathrm{~Hz}$ \\
\hline Pulse Width & $\begin{array}{l}10-20 \mathrm{~ns} \text { (corresponding to } 100 \text { to } 50 \mathrm{MHz} \\
\text { transform limited line width) }\end{array}$ & $\begin{array}{l}10-20 \mathrm{~ns} \text { (corresponding to } 100 \text { to } 50 \\
\mathrm{MHz} \text { transform limited line width) }\end{array}$ \\
\hline Spatial Mode & TEM00 & TEM00 \\
\hline Divergence & $</=0.5 \mathrm{mrad}(1 / \mathrm{e} 2$ full-width $)$ & $</=0.3 \mathrm{mrad}(1 / \mathrm{e} 2$ full-width $)$ \\
\hline Beam Quality & $\mathrm{M}^{2}<2$ & $\mathrm{M}^{2}<1.5$ \\
\hline Cooling & $\begin{array}{l}\text { Conductively cooled with interfaces for: } \\
\text { (1) coolant circulation for ground testing } \\
\text { (2) heat-pipes and radiators for space } \\
\text { (upgrade path) }\end{array}$ & $\begin{array}{l}\text { Conductively cooled with interfaces } \\
\text { for: (1) coolant circulation for ground } \\
\text { testing; (2) heat-pipes and radiators } \\
\text { for space (upgrade path) }\end{array}$ \\
\hline Lifetime & $3 \mathrm{yrs}$ & $5 \mathrm{yrs}$ \\
\hline
\end{tabular}

\section{B. Oscillator Head Design}

The first step in the system development was to design, build, and characterize a conductively-cooled, zigzag slab pump head for the oscillator. We chose to use one-sided pumped and cooled Nd:YAG slab technology that has been well developed. The zigzag slab compensates for the gain and thermal non-uniformities in the plane of the zigzag, but will not compensate for those in the orthogonal axis. Our approach to the oscillator head design of the space laser transmitter prototype is to develop a design that can demonstrate the key features needed for a flight system and can be easily modified for the flight laser transmitter.

\section{Ring Oscillator Design and Characterization}

We investigated a telescopic ring oscillator design that could achieve high beam quality, single-frequency operation, and the linear polarization preferred for the well-developed slab technology. Combining polarization output coupling with a unidirectional ring leads to linear polarization in the section of the ring containing the conductively cooled slab. By including an element with radially varying birefringence in the output coupling section, graded reflectivity output coupling is also accomplished. The combination of operating the ring as an unstable resonator plus graded reflectivity output coupling can achieve a large volume mode for efficient energy extraction, high beam quality, and a super-Gaussian profile in the output beam. The use of a reverse wave suppressor to establish unidirectional operation eliminates the need for a Faraday isolator, thus reducing both the size and weight of the final system. Figure 8 shows the ring oscillator optical schematic diagram. 


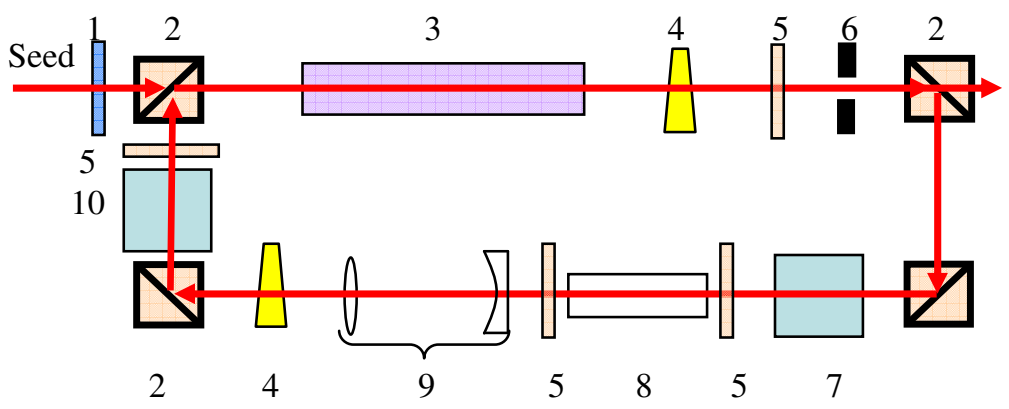

1. Reverse wave suppressor

2. Cube polarizer

3. Odd bounce slab

4. Steering wedge

5. $\lambda / 2$ waveplate

6. Mode limiting aperture

7. RTP phase modulator

8. $45^{\circ}$ Dove prism

9. Non-imaging telescope

10. RTP q-switch

Figure 8. Ring oscillator optical schematic diagram.

\section{Amplifier Design}

Two amplifier slabs are used to scale the energy from the $50 \mathrm{~mJ} /$ pulse oscillator output to the required $1 \mathrm{~J} / \mathrm{pulse}$ level at the output of the $2^{\text {nd }}$ amplifier. In order to reduce thermal lensing and improve amplifier efficiency, twosided pumping and cooling are adopted. One of the key technical issues in the design of the two-sided amplifiers is suppression of parasitic oscillations. Parasitic oscillation can be described as self-oscillation in the laser gain medium during hold-off. It is a common problem in high energy lasers. Trade studies and laboratory testing have been conducted to find the most suitable solution.

\section{E. Harmonic Generation}

$355 \mathrm{~nm}$ output is needed for direct detection Doppler winds lidar. This can be accomplished through second harmonic generation (SHG) and third harmonic generation (THG) from the oscillator/amplifier 1064nm output. Laboratory testing shows that $45-50 \%$ conversion efficiency from $1064 \mathrm{~nm}$ to $355 \mathrm{~nm}$ by using a single $10 \mathrm{~mm}$ long Type II potassium titanyl phosphate (KTP) crystal for the SHG and a10mm long Type II lithium triborate (LBO) crystal for the THG. A single down scope before all of the nonlinear crystals was used to reduce the beam size and increase the power densities to achieve high harmonic generation efficiency.

\section{F. Characterization and Testing}

The space laser transmitter prototype will be characterized and tested at Raytheon Space and Airborne Systems to verify performance and demonstrate total laser shots and reliability for the intended space-based DWL mission. In the initial performance test and verification, laser pulse energy, pulse width, pulse to pulse energy stability, beam quality, frequency stability and jitter, harmonic conversion efficiency, and wall-plug efficiency will be measured. After the initial performance verification test, key performance parameters will be monitored in a longer term reliability and life-time test. Any signs of energy degradation and component damage will be closely monitored and investigated. The purpose of the long term testing is to uncover and correct problems, if any, and demonstrate that the basic laser transmitter design is capable of meeting space DWL mission requirements.

\section{Summary}

We have presented a brief overview of our activities in Doppler winds lidar technology development and demonstrations. GroundWinds demonstrated the capability of direct detection DWL to measure atmospheric winds looking up from ground under various aerosol and very clean atmospheric conditions. BalloonWinds will validate the operation and models of a direct detection DWL looking through the entire troposphere from high altitude balloon and collect data for space-based DWL design and simulation. As a parallel effort to the GroundWinds and BalloonWinds programs, Raytheon IRAD has funded the development of a risk reduction space laser transmitter prototype to enhance technology readiness level and reduce the risk of space-based DWL development. It is our opinion that a combination of these efforts and technology development funded by NASA (e.g. LRRP and the Instrument Incubator Program) is putting the community in a position to begin a space-based hybrid DWL formulation phase study (phase A/B) in 2006-2007 with the goal to start the hardware phase in 2008 (phase C) and finally launch a hybrid DWL into space in the 2011-2012 time frame. 


\section{Acknowledgments}

The authors would like to acknowledge support by the National Oceanic and Atmospheric Administration (NOAA) for the GroundWinds and BalloonWinds programs and Raytheon IRAD for the space-based DWL riskreduction laser transmitter prototype development.

\section{References}

${ }^{1}$ World Meteorological Organization (WMO), "Preliminary statement of guidance regarding how well satellite capabilities meet WMO user requirements in several application areas", WMO Satellite Reports SAT-21. WMO/TD, No. 913, 1998.

${ }^{2}$ Emmitt, G. D., "Updated Report on Hybrid Technology DWLs", Working Group on Space-Based Lidar Winds Workshop, Oxnard, CA, Feb. 7-9, 2001.

${ }^{3}$ Menzies, R. T. and R. M. Hardesty, "Coherent Doppler Lidar for Measurements of Wind Fields," Proceedings of the IEEE, Vol. 77, No. 3, pp. 449-462, March 1989.

${ }^{4}$ Huffaker, R. M., and R. M. Hardesty, "Remote Sensing of Atmospheric Wind Velocities Using Solid-State and $\mathrm{CO}_{2}$ Coherent Laser Systems," Proceedings of The IEEE, Vol. 84, No. 2, pp. 181-204, February 1996.

${ }^{5}$ Baker, W. E., G. D. Emmitt, F. Robertson, R. M. Atlas, J. E. Molinari, D. A. Bowdle, J. Paegle, R. M. Hardesty, R. T. Menzies, T. N. Krishnamurti, R. A. Brown, M. J. Post, J. R. Anderson, A. C. Lorenc, and J. McElroy, "Lidar-Measured Winds from Space: A Key Component for Weather and Climate Prediction,” Bull. Amer. Meteor. Soc., Vol. 76, No. 6, pp. 869-888, June 1995.

${ }^{6}$ Hays, P.B., "Circle to line interferometer optical system," Appl. Opt., vol. 29, pp. 1482-1489, 1990.

${ }^{7}$ Dehring, M. T., C. A. Nardell, J. C. Pavlich, P. B. Hays, and I. G. Dors, "Performance and Comparison of 532nm and 355nm GroundWinds Lidars," Lidar Remote Sensing for Industry and Environment Monitoring III, Proceedings of SPIE, vol. 4893, 2002.

${ }^{8}$ Nardell, C.A., P. B. Hays, J. C. Pavlich, M. Dehring, G. Sypitkowski, "GroundWinds New Hampshire and the LIDARFest 2000 Campaign," Proceedings of SPIE, vol. 4484, pp. 36-50, 2001.

${ }^{9}$ Businger, S., I. Dors, S. Turco, J. Ryan, J. B. Moore, J. McHugh, T. Cherubini, C. A. Nardell, P. B. Hays, “Application of wind profiles from UV lidar in nowcasting for Mauna Kea Observatories," $12^{\text {th }}$ Symposium on Meteorological Observations and Instrumentation, American Meteo. Soc., Long Beach, CA, Feb. 9-13, 2003.

${ }^{10}$ Hovis, F. E., J. Wang, and M. Dehring, "BalloonWinds Laser Transmitter Update," Meeting of the Working Group on Space-based Lidar Winds, 28 June - 1 July 2005, Welches, OR.

${ }^{11}$ Schwemmer, G. K., "Connically scanned holographic lidar telescope," U.S. Patent 5,255,065, Oct. 19, 1993.

${ }^{12}$ Berkoff, T. A., D. N. Whiteman, R. D. Rallison, G. K. Schwemmer, L. Ramos-Izquierdo, and H. Plotkin, "Remote detection of Raman scattering by use of a holographic optical element as a dispersive telescope," vol. 25, Optics letter, pp. 1201$1203,2000$.

${ }^{13}$ Singh, U. and M. Kavaya, "Update on the NASA Laser Risk Reduction Program," Working Group on Space-Based Lidar Winds Workshop, Oxnard, CA, Feb. 17-19, 2003.

${ }^{14}$ Yu, J., U.N. Singh, N.P. Barnes, J.C. Barnes, M. Petros, M.W. Phillips, “An all solid-state 2- $\mu$ m laser system for space coherent wind lidar," IEEE Aerospace Conference Proceedings, vol.3, pp. 27-33, March 18-25, 2000.

${ }^{15}$ Yu, J., U.N. Singh, M. Kavaya, M. Petros, S. Chen, "High-energy 2- $\square \mathrm{m}$ laser development," $12^{\text {th }}$ Coherent Laser Radar Conference (CLRC), Bar Harbor, MI, June 15-20, 2003.

${ }^{16}$ Henderson, S. W., E. H. Yuen, and E. S. Fry, "Fast resonance-detection technique for single-frequency operation of injection-seeded Nd:YAG lasers," Optics Letters, Volume 11, Issue 11, 715- 718, November 1986. 